\title{
Case Selection During the COVID-19 Pandemic: Who Should Go to the Cardiac Catheterization Laboratory?
}

Evangelia Vemmou, $M D^{1}$

Ilias Nikolakopoulos, $M D^{1}$

Emmanouil S. Brilakis, MD, PhD ${ }^{1}$

Payam Dehghani, $M D^{2}$

Santiago Garcia, $M D^{1, *}$

\author{
natass \\ ${ }^{*}, 1$ Minneapolis Heart Institute and Minneapolis Heart Institute Foundation, Ab- \\ bott Northwestern Hospital, 920 E 28th Street \#300, Minneapolis, MN, 55407, \\ USA \\ Email: santiagogarcia@me.com \\ ${ }^{2}$ Prairie Vascular Research Inc., Regina, Saskatchewan, Canada
}

Published online: 18 March 2021

(C) The Author(s), under exclusive licence to Springer Science+Business Media, LLC, part of Springer Nature 2021

This article is part of the Topical Collection on Coronary Artery Disease

Keywords COVID-19 · Cardiac catheterization

\section{Abstract}

Purpose of review To summarize the best available evidence and recommendations regarding case selection for cardiac catheterization laboratory (CCL) during the coronavirus disease 2019 (COVID-19) pandemic with emphasis on ST segment elevation myocardial infarction (STEMI) management.

Recent findings The restructuring of cardiovascular services to preserve hospital beds and personal protective equipment during the COVID-19 pandemic had a profound effect on healthcare delivery around the world with unintended consequences. In the United States, a significant $38 \%$ reduction in CCL activations for STEMI was noted in the early phase of the pandemic. Similarly, a 34\% decline in utilization of invasive angiography, an $18 \%$ reduction in primary percutaneous coronary intervention (PPCI), and a $19 \%$ increase in door-to-balloon (D2B) times were also observed. These trends coincided with a significant increase in out-of-hospital cardiac arrests and late MI presentations. A shift to 
pharmacological reperfusion has been advocated in Asia, which resulted in increased morbidity and mortality.

Summary COVID-19 has negatively affected many aspects of STEMI care, including timely access to mechanical reperfusion, which has resulted in increased morbidity and mortality. Balancing optimal STEMI care with the risk of infection to healthcare workers during the pandemic is challenging. Recommendations provided by consensus documents are a helpful guidance.

\section{Introduction}

During the coronavirus disease 2019 (COVID-19) pandemic, caused by the severe acute respiratory syndrome coronavirus 2 (SARS-CoV-2), the normal function of the cardiac catheterization laboratory (CCL) has been altered to minimize the risk of personnel infection and preserve hospital beds [1]. In the present manuscript, we summarize the unintended consequences of these changes, present modified reperfusion strategies for ST segment elevation myocardial infarction (STEMI) patients during the pandemic, and discuss best available evidence regarding patient selection for cardiac catheterization during the pandemic.

\section{Myocardial injury and COVID-19}

The frequency of myocardial injury depends on the method of detection (fourth generation, high-sensitivity cardiac troponins (hs cTn), or cardiac magnetic resonance imaging), frequency of sampling, and illness severity. In the largest study to date [2], myocardial injury defined as cardiac troponin (cTn) increase above the 99th percentile was found in $36 \%$ of hospitalized patients with COVID-19 and was associated with higher incidence of adverse outcomes including mortality, a finding similar to other acute respiratory diseases [3•]. Nevertheless, the frequency of myocardial injury assessed by cardiac troponins in COVID-19 varies greatly between studies, ranging from 1\% in COVID-19 survivors to $100 \%$ in patients with very severe forms of COVID-19 [3•]. This is likely due to inclusion of different patient populations in each study, given that patients with myocardial injury are more likely to be critically ill and have higher prevalence of chronic cardiovascular conditions.

Another study evaluated 100 patients recently recovered from COVID-19 infection with cMRI and found abnormal findings in $78 \%$ of them including abnormal CMR raised myocardial native T1 $(n=73)$, raised myocardial native T2 $(n=60)$, myocardial late gadolinium enhancement $(n=32)$, or pericardial enhancement $(n=22)$ [4].

With serial cTn measurements, myocardial injury due to COVID-19 can be classified as acute (delta $>20 \%$ ) or chronic (delta $<20 \%$ ). Acute injury cases can be either ischemic if there is a clinical correlate of myocardial ischemia (i.e. wall motion abnormality) or nonischemic, such as acute heart failure, pulmonary embolism [5], or less commonly stress cardiomyopathy [6] or myocarditis. Chronic injury manifests as mild cTn elevation and is typically seen in patients with pre-existing cardiovascular conditions such as heart failure and hypertension and portends a bad prognosis [3•]. In an echocardiographic assessment of 
consecutive hospitalized COVID-19 patients, myocardial injury correlated with higher prevalence of right and left ventricular diastolic dysfunction; however, the left ventricular ejection fraction remained normal in most patients with elevated cTn, indicating that lung disease causing right heart failure is the main contributor of troponin elevation in COVID-19 patients [7]. Indeed, in a study involving 799 moderately to severely ill COVID-19 patients, clinical heart failure complicated the hospitalization of $24 \%$ and amino-terminal pro-Btype natriuretic peptide levels (BNPs) were elevated in $23 \%$ of all patients [8]. Also, in an autopsy study of 21 COVID-19 patients, the principal cardiac pathological changes were diffuse macrophage infiltration (possibly due to COVID-19-induced inflammation or due to underlying conditions) and right ventricular strain, with lymphocytic myocarditis being a less common finding [9]. Experts recommend serial testing with hs-cTn and BNP in all hospitalized patients with COVID-19 infection for risk stratification and prognosis [3•].

\section{Management of ST segment elevation myocardial infarction during the COVID-19 pandemic}

Prior to COVID-19, primary percutaneous coronary intervention (PPCI) was considered the treatment of choice for STEMI patients presenting to a PCIcapable hospital or who could be transferred to and treated in a PCI-capable hospital within 120 min of presentation [10].

The need to protect CCL personnel and patients from COVID-19 coupled with shortages of personnel protective equipment (PPE) and lack of rapid testing to confirm COVID-19 infection has significantly disrupted STEMI systems of care. Given these considerations, cardiology societies around the globe have taken different approaches to STEMI management during the pandemic. The American College of Cardiology (ACC)/American Heart Association (AHA) and Society for Cardiac Angiography and Interventions (SCAI) continue to recommend PPCI for patients with STEMI (Fig. 1).

In contrast, experts in China, Jordan, Palestine, and Iran recommend prioritizing thrombolytic therapy for most patients with unconfirmed COVID-19 status [11]. The Chinese experience with this modified approach has recently been published [11]. In Hubei province, the percentage of patients receiving PPCI dropped by $50 \%$ and the probability of receiving thrombolytic therapy increased sharply during the outbreak (odds ratio 4.78, 95\% CI: 2.45-9.33, $p<0.001$ ). Overall, the proportion of patients receiving timely reperfusion decreased from 59 to $51 \%$ and among patients receiving PPCI, a 20-min delay was noted in Hubei. Inhospital mortality increased from 4.6 to $7.3 \%$ and risk of heart failure also increased from 14.2 to $18.4 \%$ in Hubei during the outbreak.

In the United States (US), a significant $38 \%$ reduction in CCL activations for STEMI was documented in the early phase of the pandemic [12•]. A follow-up, expanded analysis that included 18 healthcare systems in the US showed that the number of CCL activations leading to angiography dropped by $34 \%$ and number of CCL activations leading to PPCI dropped by $20 \%$ whereas the average door to balloon time increased by $20 \%$ [13]. These negative trends in STEMI care coincided with 


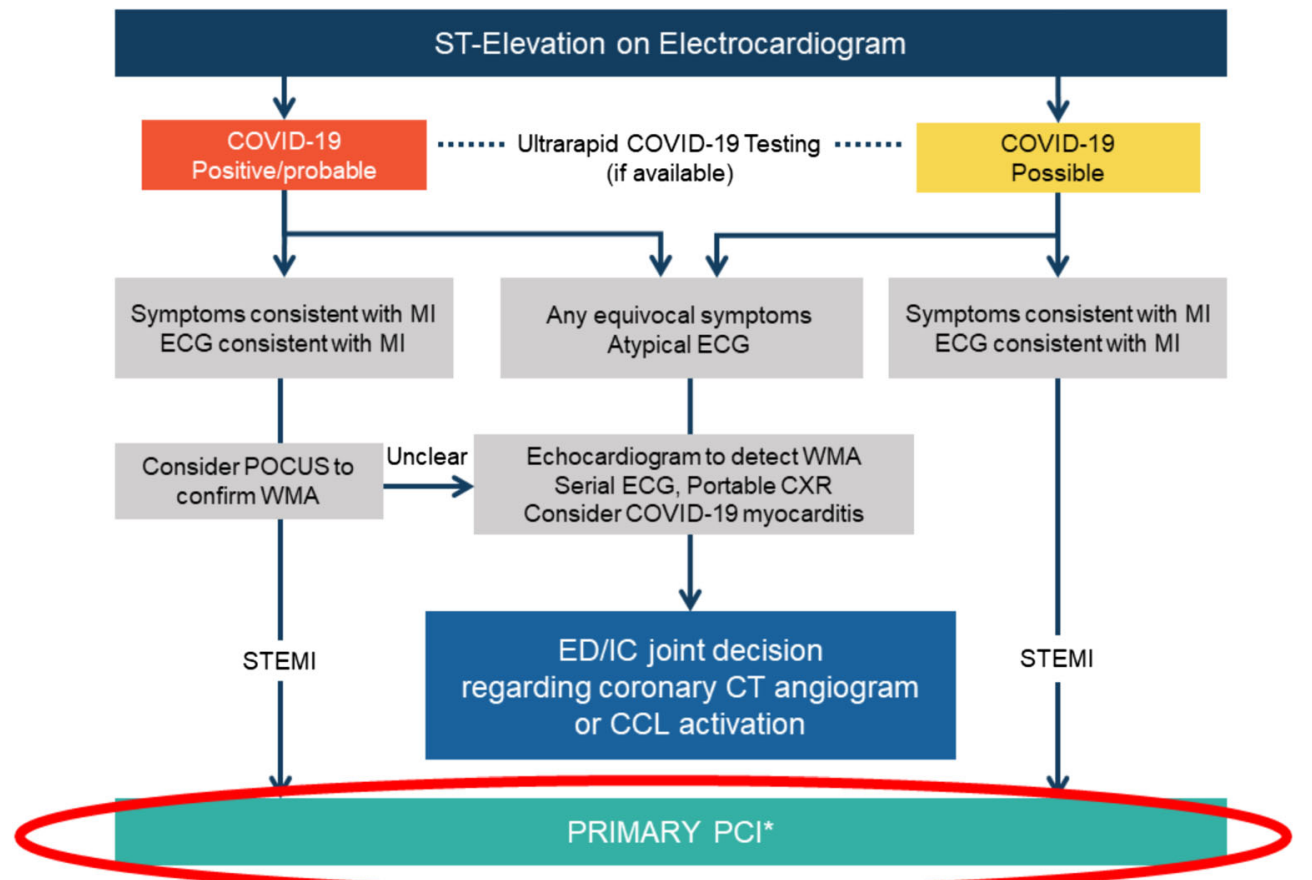

Fig. 1. Pathways for management of patients with suspected ST-Segment elevation myocardial infarction (STEMI) during hre pandemic. Primary PCI (PPCI) remains the preferred reperfusion modality

a significant increase in the number of out-of-hospital cardiac arrest (OHCA) in various cities affected by COVID-19 lockdowns [14, 15]. The underlying reasons for these unexpected trends are not entirely clear and multiple factors may be playing a role including patients not seeking care out of fear of contracting COVID-19, inability to see doctors during the lockdown, and others. As the US prepares for a second wave of COVID-19 in the fall and winter, it is imperative to educate the public, preserve essential services to care for non-COVID patients with acute cardiovascular emergencies, and continue to observe these trends periodically.

\section{STEMI in patients with confirmed COVID-19 infection}

A summary of published studies including STEMI patients with COVID19 at the time of this writing is presented in Table 1. As noted in the table, wide variations in mortality have been reported likely due to variations in patients included, reperfusion strategies, and utilization of invasive angiography.

To overcome some of these limitations, SCAI and the Canadian Association of Interventional Cardiology (CAIC) in conjunction with the ACC Interventional Council have collaborated to create a multicenter observational registry, North American COVID-19 ST Segment Elevation Myocardial Infarction (NACMI). This registry is enrolling confirmed COVID-19 patients and persons under investigation (PUIs) with new ST segment elevation or new-onset left bundle branch block (LBBB) 


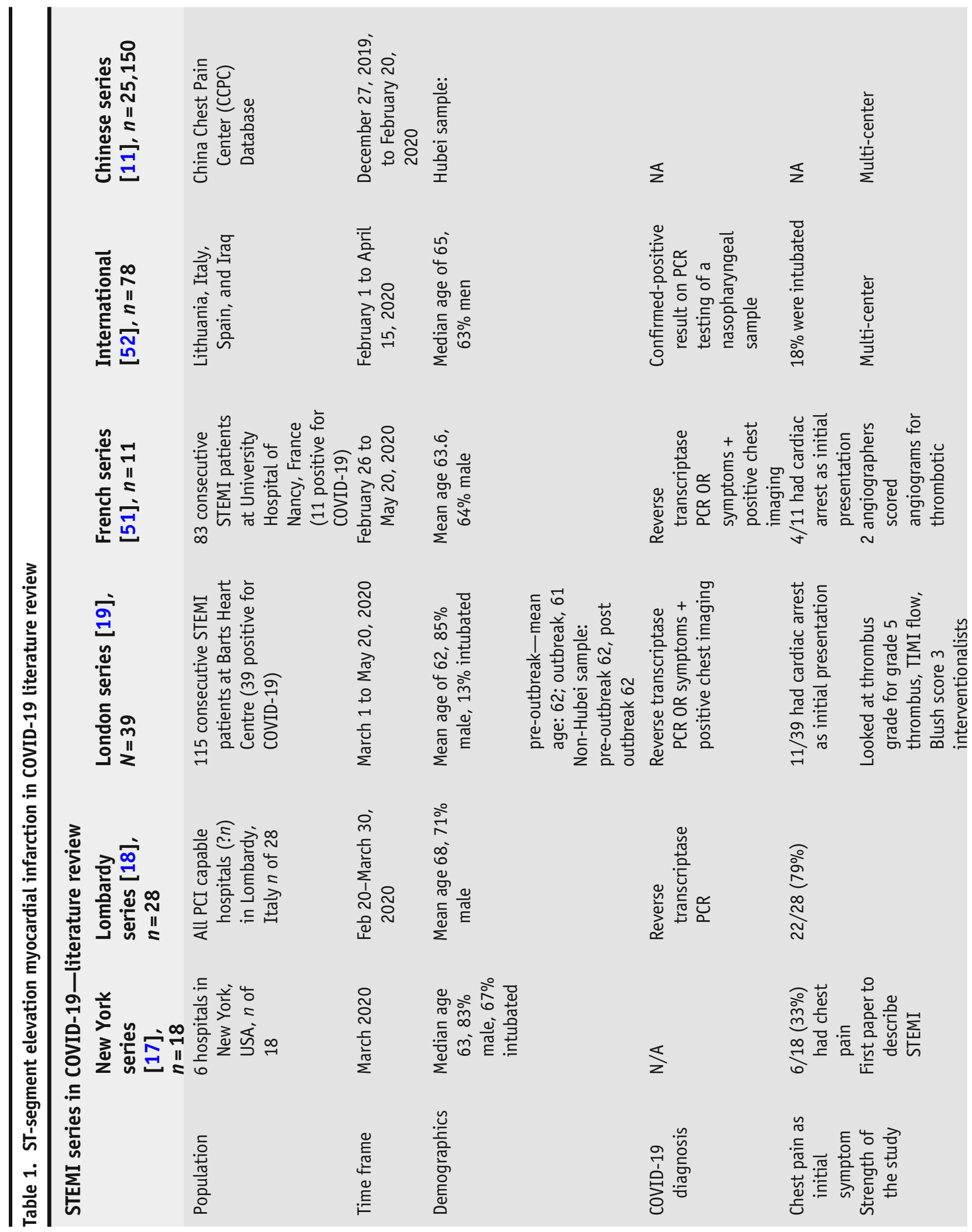




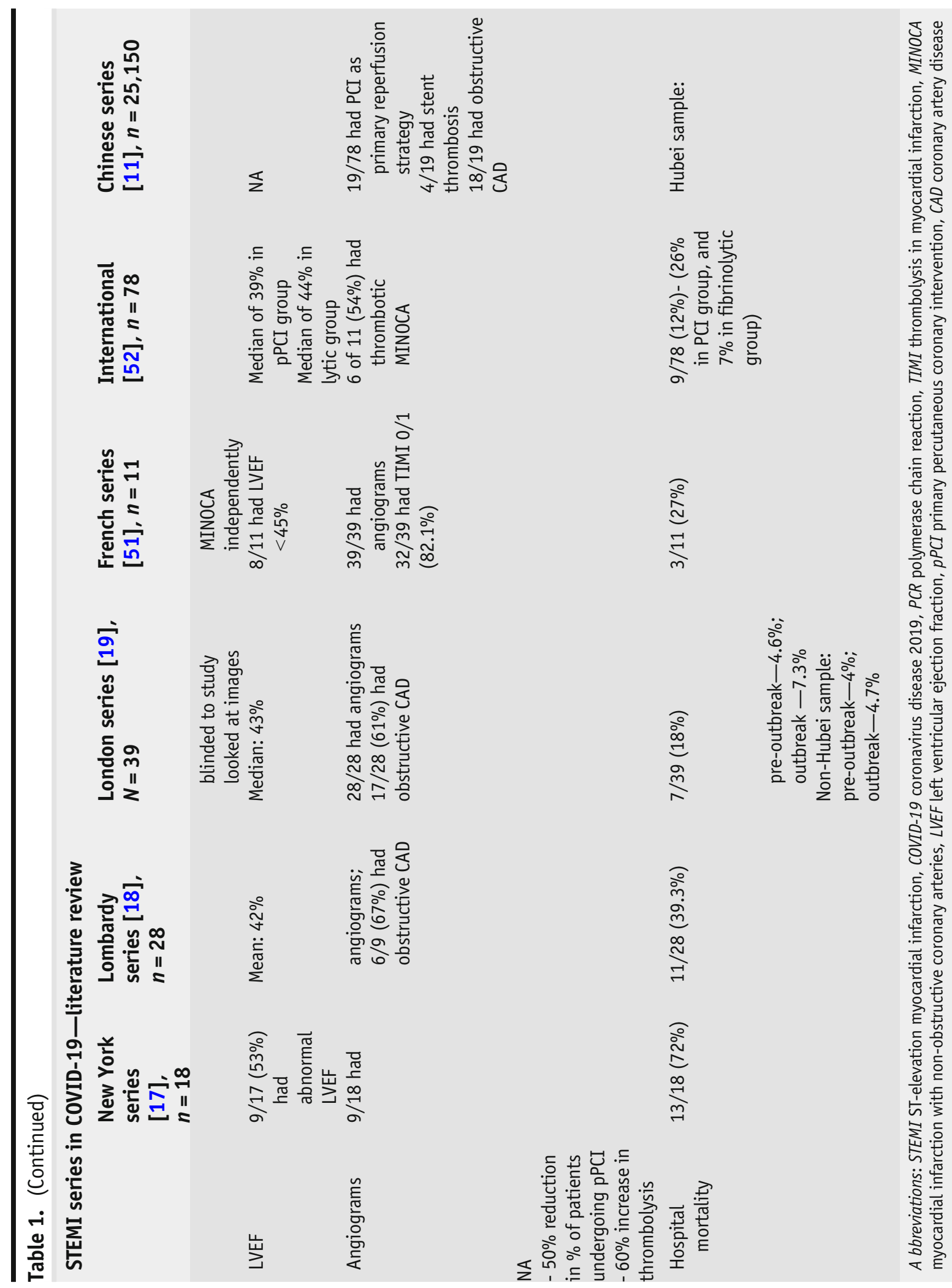




\section{Angiographic findings}

on electrocardiogram (ECG). The primary objective of this registry is to compare demographics, comorbidities, and pertinent diagnostic and management data between COVID-19 confirmed STEMI patients with a historical cohort of STEMI patients prior to the COVID-19 crisis. The primary endpoint is in-hospital and 1-year major adverse cardiovascular events (MACEs) defined as composite of all-cause mortality, stroke, recurrent MI, and repeat unplanned revascularization [16].

\section{Cardiogenic shock}

Of 18 COVID-19-positive patients presenting with ST segment elevation to 6 New York City hospitals, 8 were classified as having a typical STEMI on the basis of clinical presentation and angiographic findings whereas 10 had non coronary myocardial injury [17]. Of note, this diagnosis was made on the basis of clinical presentation, biomarkers, and echocardiography since only 9 (50\%) underwent invasive angiography. Importantly, only 33\% had chest pain, 39\% had shock, and $11 \%$ cardiac arrest. In-hospital mortality was $72 \%$.

Similarly, among 28 COVID-19 patients with chest pain and localized ST elevation in Northern Italy, 11 (39.3\%) did not have obstructive coronary artery disease [18]. Among 115 STEMI patients admitted during a 12week period at Barts Health Centre, 39 were COVID-19-positive, and COVID-19 positivity was associated with higher D-dimer levels (median, 1.86; interquartile range [IQR], $0.98-6.6$ vs median, 0.52 ; IQR $0.40-1, p=$ $0.0012)$, and higher rates of multivessel thrombosis $(17.9 \%$ vs $0 \%, p=$ $0.0003)$, stent thrombosis $(10.3 \%$ vs $1.2 \%, p=0.0445)$, and modified thrombus grade $(4-5)(75 \%$ vs $31.4 \%, p=0.0006)$ [19]. In-hospital mortality was numerically higher in COVID-19 patients $(17.9 \%$ vs $6.5 \%, p=$ 0.1 , who also had higher rates of cardiovascular comorbidities such as diabetes mellitus and hypertension [19].

In the Barts study, rates of cardiogenic shock were similar among STEMI patients with and without COVID-19 (15.4\% vs $10.5 \%, p=0.549)$ [19]. Nevertheless, STEMI with cardiogenic shock in patients with already established COVID-19 infection can be fatal [20]. Cardiogenic shock can also develop in COVID-19 patients with myocarditis, stress cardiomyopathy, or pulmonary embolism with unfavorable outcome [21].

\section{Mechanical circulatory support}

Extracorporeal membrane oxygenation (ECMO) may have a role in COVID-19related acute respiratory failure with refractory hypoxemia [22]. However, initial reports of patients with COVID-19 requiring ECMO suggested mortality rates higher than $90 \%$ [23].

Schmidt et al. studied 83 patients that were treated for COVID-19 in the intensive care units in the Paris-Sorbonne University Hospital Network, including 61 patients who received ECMO. At 60 days post ECMO initiation, the 
estimated probability of death was 31\% (95\% CI 22-42) [24].

Barbaro et al. [25] studied 1035 patients with COVID-19 who received ECMO support at 213 hospitals in 36 countries. Their study showed that the estimated cumulative incidence of in-hospital mortality 90 days after the initiation of ECMO was $37.4 \%$ (95\% CI 34.4-40.4). The results were similar when only patients who were characterized as having acute respiratory distress syndrome (ARDS) (74\% of the study cohort) were included in the analysis.

The ongoing COVID-19 Mechanical Circulatory Support (MCS) registry will provide more information into short- and long-term outcomes of these patients.

Although most cases of myocardial injury in COVID-19 patients are not associated with myocarditis [26], myocarditis in patients with COVID-19 presenting with ST segment elevation has been described in isolated case reports [27-31].

\section{Triage prior to coming to the cardiac catheterization laboratory}

\section{STEMI}

The triage of STEMI patients during the pandemic comprises four pillars:

(a) initial emergency department evaluation, with focused history and physical exam as well as chest x-ray and ultra-rapid COVID-19 testing (if available) to determine probability of COVID-19 infection; (b) use of point-of-care ultrasound to detect regional wall motion abnormalities prior to PPCI in positive/probable COVID-19 patients having clinical and electrocardiographic presentation consistent with STEMI; (c) immediate PPCI in COVID-19 possible patients having clinical and electrocardiographic presentation consistent with STEMI; and (d) use of echocardiogram, serial electrocardiograms, and cTn and possible computed tomography angiography in patients without typical clinical and electrocardiographic presentation [32•, 33, 34].

Upon decision for revascularization, all COVID-19-positive/probable patients should be transferred to a dedicated COVID-19 laboratory and then to an isolated intensive care unit [32•]. Fibrinolysis is not recommended by ACC/AHA/SCAI due to its suboptimal efficacy compared with PPCI [35-37] and potential need for rescue PCI, especially given that it can increase bleeding risk while having no benefit in a large proportion of COVID-19 patients with STEMI who have non-obstructive coronary arteries [18]. It could however be used as part of a pharmacoinvasive strategy [35] in cases when the patient is at a referral center and a long delay is anticipated [36], followed by repeat electrocardiogram and PCI.

The majority of patients with NSTEMI can undergo rapid COVID testing prior to coming to the CCL. High-risk non-STEMI patients (e.g., with hypotension/shock, refractory chest pain, acute heart failure, lifethreatening arrhythmia) should be managed with early $(<2 \mathrm{~h})$ 
angiography, while the remaining patients can either be transferred to the cardiac care unit and undergo catheterization within 1 day (if COVID-19-negative) or receive medical management with possible catheterization in a COVID-19 hospital if symptoms do not recede (COVID19-positive or under investigation) [1].

\section{Personal protective equipment}

\section{Personal protective equipment considerations for catheterization laboratory personnel}

Ensuring adequate personal protection of all catheterization laboratory members is critical. Cardiovascular teams in China published in March 2020 an algorithm for performing procedures in the safest possible environment but the applicability of these policies is limited to cardiovascular systems with access to rapid testing protocols for the diagnosis of COVID-19 [38]. There are significant delays in COVID testing in some countries and situations where emergent activation of the catheterization laboratory is required. The Society for Cardiovascular Angiography and Interventions (SCAI), the American College of Cardiology (ACC), and the American College of Emergency Physicians (ACEP) published a consensus document stating that patients requiring emergent activation of the catheterization laboratory should be treated as COVID19 possible [32・].

PCI for STEMI and out-of-hospital cardiac arrest are situations during which patients might require bi-level or continuous positive pressure ventilation, intubation/extubation, defibrillation with the need for cardiopulmonary resuscitation, and airway suctioning. In these circumstances, aerosol transmission can occur [39]; hence, healthcare workers performing PCI for these patients should wear personal protective equipment that minimizes potential aerosol transmission [32•].

\section{Access to PPE}

ACC's Interventional Council and SCAI's consensus document states that all catheterization laboratory personnel should be fit-tested for N95 masks, have eye masks, and receive training for doffing and donning equipment [40]. A multinational survey by Banerjee et al. conducted in April 2020 showed that, although access to personal protective equipment was universal $(95 \%)$, the type of equipment available was diverse. For example, FIT-tested N95 or equivalent masks were not available to $30 \%$ of the respondents of this survey [41]. Universal masking at a large healthcare system in the United States was associated with significantly lower rate of SARS-CoC-2 infection among healthcare workers [42].

The World Health Organization recommends using medical masks for regular care of COVID-19 patients in the context of droplet and contact precautions and respirators for circumstances and settings where aerosol transmission can occur [43]. The individual components of PPE as used by an interventional cardiologist before a STEMI procedure can be found in SCAI, ACC, and ACEP guidelines [32•]. 


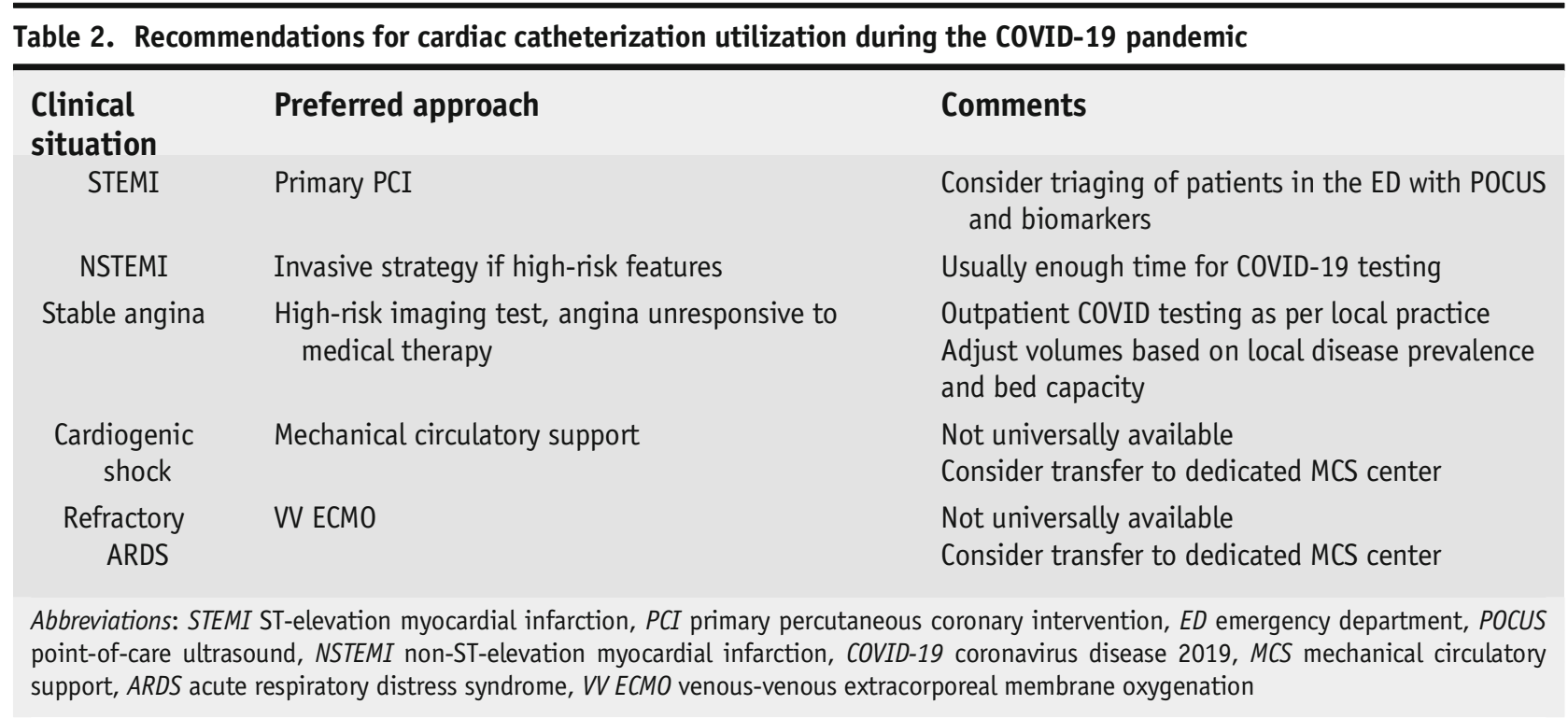

\section{Other procedures}

Apart from reduced STEMI procedures, other procedures have been affected. In the US, a national survey of catheterization laboratory directors and interventional cardiologists conducted in May 2020 showed that likelihood of deferral decreased as the urgency of the procedure increased and the majority deferred left atrial appendage closure and transcatheter mitral valve replacement. In the setting of deferred angiograms, the majority of the respondents of this survey reported that they were more likely to use imaging studies (nuclear perfusion scanning, coronary CT angiography, stress echocardiography) to risk stratify patients [44].

\section{Safe reintroduction of cardiovascular services}

The North American Society Leadership provided an ethical framework and guidance for safe reintroduction of cardiovascular procedures [45], based on recommendations from North American Cardiovascular Societies [20, 32•, 4650]. The authors' recommendations are summarized in Table 2.

\section{Conclusion}

Balancing optimal care while minimizing the risk of COVID-19 infection can be challenging. Recommendations provided by consensus documents are a helpful guidance. Ongoing observational registries such as NACMI have the potential to inform clinical decision-making and improve patient care.

\section{Code availability}

Not applicable 


\section{Authors' contributions}

Literature search and drafting of the manuscript were performed by Evangelia Vemmou, Ilias Nikolakopoulos, and Santiago Garcia. All authors read, critically revised, and approved the final manuscript.Data availabilityNot applicable

\section{Compliance with Ethical Standards}

\section{Conflict of Interest}

Dr. Brilakis: consulting/speaker honoraria from Abbott Vascular, American Heart Association (associate editor Circulation), Amgen, Biotronik, Boston Scientific, Cardiovascular Innovations Foundation (Board of Directors), ControlRad, CSI, Ebix, Elsevier, GE Healthcare, InfraRedx, Medtronic, Siemens, and Teleflex; research support from Regeneron and Siemens. Shareholder: MHI Ventures. Dr. Garcia is a consultant for Edwards Lifesciences and Abbott Vascular. He has received institutional research grants from BSCI, Abbott Vascular, Edwards Lifesciences and Medtronic.

Evangelia Vemmou declares that she has no conflict of interest. Ilias Nikolakopoulos declares that he has no conflict of interest. Payam Dehghani declares that he has no conflict of interest.

\section{Human and Animal Rights and Informed Consent}

This article does not contain any studies with human or animal subjects performed by any of the authors.

\section{References and Recommended Reading}

Papers of particular interest, published recently, have been highlighted as:

- Of importance

1. Szerlip M, Anwaruddin S, Aronow HD, Cohen MG, Daniels MJ, Dehghani P, et al. Considerations for cardiac catheterization laboratory procedures during the COVID-19 pandemic perspectives from the Society for Cardiovascular Angiography and Interventions Emerging Leader Mentorship (SCAI ELM) Members and Graduates. Catheter Cardiovasc Interv. 2020;96(3):586-97. https://doi.org/10.1002/ccd. 28887.

2. Lala A, Johnson KW, Januzzi JL, Russak AJ, Paranjpe I, Richter F, et al. Prevalence and impact of myocardial injury in patients hospitalized with COVID-19 infection. J Am Coll Cardiol. 2020;76:533-46.

3.• Sandoval Y, Januzzi JL Jr, Jaffe AS. Cardiac troponin for assessment of myocardial injury in COVID-19: JACC Review Topic of the Week. J Am Coll Cardiol. 2020;76:1244-5.

This articles provides a contemporary review on the role of cardiac troponins in the diagnosis and risk stratification of patients with COVID-19.

4. Puntmann VO, Carerj ML, Wieters I, Fahim M, Arendt C, Hoffmann J, et al. Outcomes of cardiovascular magnetic resonance imaging in patients recently recovered from coronavirus disease 2019 (COVID-19).
JAMA Cardiol. 2020;5:1265-73. https://doi.org/10. 1001/jamacardio.2020.3557.

5. Thachil J, Tang N, Gando S, Falanga A, Cattaneo M, Levi $\mathrm{M}$, et al. ISTH interim guidance on recognition and management of coagulopathy in COVID-19. J Thromb Haemost. 2020;18(5):1023-6. https://doi.org/10. $1111 /$ jth. 14810 .

6. Giustino G, Croft LB, Oates CP, Rahman K, Lerakis S, Reddy VY, et al. Takotsubo cardiomyopathy in COVID19. J Am Coll Cardiol. 2020;76(5):628-9. https://doi. org/10.1016/j.jacc.2020.05.068.

7. Szekely Y, Lichter Y, Taieb P, Banai A, Hochstadt A, Merdler I, et al. Spectrum of cardiac manifestations in COVID-19. Circulation. 2020;142(4):342-53. https:// doi.org/10.1161/CIRCULATIONAHA.120.047971.

8. Chen T, Wu D, Chen H, Yan W, Yang D, Chen G, et al. Clinical characteristics of 113 deceased patients with coronavirus disease 2019: retrospective study. BMJ (Clinical Research Ed). 2020;368:m1091. https://doi. org/10.1136/bmj.m1091.

9. Basso C, Leone O, Rizzo S, De Gaspari M, van der Wal AC, Aubry M-C, et al. Pathological features of COVID19-associated myocardial injury: a multicentre cardiovascular pathology study. Eur Heart J. 2020;41:382735. https://doi.org/10.1093/eurheartj/ehaa664. 
10. O'Gara PT, Kushner FG, Ascheim DD, Casey DE, Chung MK, Lemos JA, et al. 2013 ACCF/AHA guideline for the management of ST-elevation myocardial infarction. Circulation. 2013;127(4):e362-425. https:// doi.org/10.1161/CIR.0b013e3182742cf6.

11. Xiang D, Xiang X, Zhang W, Yi S, Zhang J, Gu X, et al. Management and outcomes of patients with STEMI during the COVID-19 pandemic in China. J Am Coll Cardiol. 2020;76(11):1318-24. https://doi.org/10. 1016/j.jacc.2020.06.039.

12. Garcia S, Albaghdadi MS, Meraj PM, Schmidt C, Garberich R, Jaffer FA, et al. Reduction in ST-segment elevation cardiac catheterization laboratory activations in the United States during COVID-19 pandemic. J Am Coll Cardiol. 2020;75(22):2871-2. https://doi.org/10. 1016/j.jacc.2020.04.011

This was the first observation documenting a significant reduction in cardiac catheterization activations for STEMI in the USA.

13. Garcia S, Stanberry L, Schmidt C, Sharkey S, Megaly M, Albaghdadi MS, et al. Impact of COVID-19 pandemic on STEMI care: an expanded analysis from the United States. Catheter Cardiovasc Interv. 2020. https://doi. org/10.1002/ccd.29154.

14. Lai PH, Lancet EA, Weiden MD, Webber MP, ZeigOwens R, Hall CB, et al. Characteristics associated with out-of-hospital cardiac arrests and resuscitations during the novel coronavirus disease 2019 pandemic in New York City. JAMA Cardiol. 2020;5:1154. https:// doi.org/10.1001/jamacardio.2020.2488.

15. Marijon E, Karam N, Jost D, Perrot D, Frattini B, Derkenne C, et al. Out-of-hospital cardiac arrest during the COVID-19 pandemic in Paris, France: a population-based, observational study. Lancet Public Health. 2020;5(8):e437-e43. https://doi.org/10.1016/S24682667(20)30117-1.

16. Dehghani P, Davidson LJ, Grines CL, Nayak K, Saw J, Kaul P, et al. North American COVID-19 ST-SegmentElevation Myocardial Infarction (NACMI) registry: rationale, design, and implications. Am Heart J. 2020;227:11-8. https://doi.org/10.1016/j.ahj.2020. 05.006 .

17. Bangalore S, Sharma A, Slotwiner A, Yatskar L, Harari $\mathrm{R}$, Shah B, et al. ST-segment elevation in patients with Covid-19 - a case series. N Engl J Med.

2020;382(25):2478-80. https://doi.org/10.1056/ NEJMc2009020.

18. Stefanini GG, Montorfano $M$, Trabattoni D, Andreini D, Ferrante G, Ancona M, et al. ST-elevation myocardial infarction in patients with COVID-19. Circulation. 2020;141(25):2113-6. https://doi.org/10.1161/ CIRCULATIONAHA.120.047525.

19. Choudry FA, Hamshere SM, Rathod KS, Akhtar MM, Archbold RA, Guttmann OP, et al. High thrombus burden in patients with COVID-19 presenting with STsegment elevation myocardial infarction. J Am Coll
Cardiol. 2020;76(10):1168-76. https://doi.org/10. 1016/j.jacc.2020.07.022.

20. Shah PB, Welt FGP, Mahmud E, Phillips A, Kleiman NS, Young MN, et al. Triage considerations for patients referred for structural heart disease intervention during the COVID-19 pandemic: an ACC/SCAI position statement. JACC Cardiovasc Interv. 2020;13(12):1484-8. https://doi.org/10.1016/j.jcin. 2020.04.001.

21. Sánchez-Recalde Á, Solano-López J, Miguelena-Hycka J, Martín-Pinacho JJ, Sanmartín M, Zamorano JL. COVID-19 and cardiogenic shock. Different cardiovascular presentations with high mortality. Rev Esp Cardiol (Engl Ed). 2020;73(8):669-72. https://doi. org/10.1016/j.rec.2020.04.012.

22. MacLaren G, Fisher D, Brodie D. Preparing for the Most critically ill patients with COVID-19: the potential role of extracorporeal membrane oxygenation. Jama. 2020;323(13):1245-6. https://doi.org/10.1001/jama. 2020.2342.

23. Henry BM, Lippi G. Poor survival with extracorporeal membrane oxygenation in acute respiratory distress syndrome (ARDS) due to coronavirus disease 2019 (COVID-19): pooled analysis of early reports. J Crit Care. 2020;58:27-8. https://doi.org/10.1016/j.jcrc. 2020.03.011.

24. Schmidt M, Hajage D, Lebreton G, Monsel A, Voiriot G, Levy D, et al. Extracorporeal membrane oxygenation for severe acute respiratory distress syndrome associated with COVID-19: a retrospective cohort study. Lancet Respir Med. 2020;8:1121-31. https://doi.org/10.1016/ s2213-2600(20)30328-3.

25. Barbaro RP, MacLaren G, Boonstra PS, Iwashyna TJ, Slutsky AS, Fan E, et al. Extracorporeal membrane oxygenation support in COVID-19: an international cohort study of the Extracorporeal Life Support Organization registry. Lancet. 2020. https://doi.org/10.1016/ S0140-6736(20)32008-0.

26. Deng Q, Hu B, Zhang $\mathrm{Y}$, Wang $\mathrm{H}$, Zhou $\mathrm{X}, \mathrm{Hu} \mathrm{W}$, et al. Suspected myocardial injury in patients with COVID19: evidence from front-line clinical observation in Wuhan, China. Int J Cardiol. 2020;311:116-21. https://doi.org/10.1016/j.ijcard.2020.03.087.

27. Hu H, Ma F, Wei X, Fang Y. Coronavirus fulminant myocarditis treated with glucocorticoid and human immunoglobulin. Eur Heart J. 2020. https://doi.org/ 10.1093/eurheartj/ehaa190.

28. Tavazzi G, Pellegrini C, Maurelli M, Belliato M, Sciutti F, Bottazzi A, et al. Myocardial localization of coronavirus in COVID-19 cardiogenic shock. Eur J Heart Fail. 2020;22(5):911-5. https://doi.org/10.1002/ejhf.1828.

29. Zeng J-H, Liu Y-X, Yuan J, Wang F-X, Wu W-B, Li J-X, et al. First case of COVID-19 complicated with fulminant myocarditis: a case report and insights. Infection. 2020;48:1-5. https://doi.org/10.1007/s15010-02001424-5. 
30. Kim I-C, Kim JY, Kim HA, Han S. COVID-19-related myocarditis in a 21-year-old female patient. Eur Heart J. 2020;41(19):1859. https://doi.org/10.1093/ eurheartj/ehaa288.

31. Sala S, Peretto G, Gramegna M, Palmisano A, Villatore A, Vignale D, et al. Acute myocarditis presenting as a reverse Tako-Tsubo syndrome in a patient with SARSCoV-2 respiratory infection. Eur Heart J.

2020;41(19):1861-2. https://doi.org/10.1093/ eurheartj/ehaa286.

32. Mahmud E, Dauerman HL, FGP W, Messenger JC, Rao SV, Grines C, et al. Management of acute myocardial infarction during the COVID-19 pandemic: a Consensus Statement from the Society for Cardiovascular Angiography and Interventions (SCAI), the American College of Cardiology (ACC), and the American College of Emergency Physicians (ACEP). Catheter Cardiovasc Interv. 2020;96(2):336-45. https://doi.org/10.1002/ccd.28946

This article summarizes current recommendations from SCAI/ACC/ACEP regarding the management of acute myocardial indarction during COVID-19 pandemic.

33. Yerasi C, Case BC, Forrestal BJ, Chezar-Azerrad C, Hashim H, Ben-Dor I, et al. Treatment of ST-segment elevation myocardial infarction during COVID-19 pandemic. Cardiovasc Revasc Med. 2020:S15538389(20)30299-2. https://doi.org/10.1016/j.carrev. 2020.05.027.

34. Chieffo A, Stefanini GG, Price S, Barbato E, Tarantini G, Karam N, et al. EAPCI position statement on invasive management of acute coronary syndromes during the COVID-19 pandemic. Eur Heart J. 2020;41(19):183951. https://doi.org/10.1093/eurheartj/ehaa381.

35. Fazel R, Joseph TI, Sankardas MA, Pinto DS, Yeh RW, Kumbhani DJ, et al. Comparison of reperfusion strategies for ST-segment-elevation myocardial infarction: a multivariate network meta-analysis. J Am Heart Assoc. 2020;9(12):e015186. https://doi.org/10.1161/jaha. 119.015186

36. Engel Gonzalez P, Omar W, Patel KV, de Lemos JA, Bavry AA, Koshy TP, et al. Fibrinolytic strategy for STsegment-elevation myocardial infarction: a contemporary review in context of the COVID-19 pandemic. Circ Cardiovasc Interv. 2020;13(9):e009622. https://doi. org/10.1161/circinterventions.120.009622.

37. Kirtane AJ, Bangalore S. Why Fibrinolytic therapy for ST-segment-elevation myocardial infarction in the COVID-19 pandemic is not your new best friend. Circ Cardiovasc Qual Outcomes. 2020;13(6):e006885. https://doi.org/10.1161/circoutcomes.120.006885.

38. Zeng J, Huang J, Pan L. How to balance acute myocardial infarction and COVID-19: the protocols from Sichuan Provincial People's Hospital. Intensive Care Med. 2020;46(6):1111-3. https://doi.org/10.1007/ s00134-020-05993-9.

39. Tran K, Cimon K, Severn M, Pessoa-Silva CL, Conly J. Aerosol generating procedures and risk of transmission of acute respiratory infections to healthcare workers: a systematic review. PLoS One. 2012;7(4):e35797. https://doi.org/10.1371/journal.pone.0035797.

40. Welt FGP, Shah PB, Aronow HD, Bortnick AE, Henry $\mathrm{TD}$, Sherwood MW, et al. Catheterization laboratory considerations during the coronavirus (COVID-19) pandemic: from the ACC's Interventional Council and SCAI. J Am Coll Cardiol. 2020;75(18):2372-5. https:// doi.org/10.1016/j.jacc.2020.03.021.

41. Banerjee S, Tarantini G, Abu-Fadel M, Banerjee A, Little BB, Sorajja P, et al. Coronavirus disease 2019 catheterization laboratory survey. J Am Heart Assoc. 2020;9(15):e017175. https://doi.org/10.1161/JAHA. 120.017175 .

42. Wang X, Ferro EG, Zhou G, Hashimoto D, Bhatt DL. Association between universal masking in a health care system and SARS-CoV-2 positivity among health care workers. JAMA. 2020;324(7):703-4. https://doi.org/ 10.1001/jama.2020.12897.

43. WHO Infection Prevention and Control Guidance for COVID-19 https://www.who.int/emergencies/ diseases/novel-coronavirus-2019/technical-guidance/ infection-prevention-and-control. 2020.

44. Yong CM, Ang L, Welt FGP, Gummidipundi S, Henry TD, Pinto DS, et al. Cardiac procedural deferral during the coronavirus (COVID-19) pandemic. Catheter Cardiovasc Interv. 2020;96:1080-6. https://doi.org/ 10.1002/ccd.29262.

45. Wood DA, Mahmud E, Thourani VH, Sathananthan J, Virani A, Poppas A, et al. Safe reintroduction of cardiovascular services during the COVID-19 pandemic: from the North American Society Leadership. J Am Coll Cardiol. 2020;75(25):3177-83. https://doi.org/10. 1016/j.jacc.2020.04.063.

46. Wood DA, Sathananthan J, Gin K, Mansour S, Ly HQ, Quraishi AU, et al. Precautions and procedures for coronary and structural cardiac interventions during the COVID-19 pandemic: Guidance from Canadian Association of Interventional Cardiology. Can J Cardiol. 2020;36(5):780-3. https://doi.org/10.1016/j. cjca.2020.03.027.

47. Kirkpatrick JN, Mitchell C, Taub C, Kort S, Hung J, Swaminathan M. ASE statement on protection of patients and echocardiography service providers during the 2019 novel coronavirus outbreak: endorsed by the American College of Cardiology. J Am Coll Cardiol. 2020;75(24):3078-84. https://doi.org/10.1016/j.jacc. 2020.04.002.

48. Choi AD, Abbara S, Branch KR, Feuchtner GM, Ghoshhajra B, Nieman K, et al. Society of Cardiovascular Computed Tomography guidance for use of cardiac computed tomography amidst the COVID-19 pandemic endorsed by the American College of Cardiology. J Cardiovasc Comput Tomogr. 2020;14(2):101-4. https://doi.org/10.1016/j.jcct. 2020.03.002. 
49. Haft JW, Atluri P, Ailawadi G, Engelman DT, Grant $\mathrm{MC}$, Hassan A, et al. Adult cardiac surgery during the COVID-19 pandemic: a tiered patient triage guidance statement. J Thorac Cardiovasc Surg.

2020;160(2):452-5. https://doi.org/10.1016/j.jtcvs. 2020.04.011.

50. Hassan A, Arora RC, Adams C, Bouchard D, Cook R, Gunning D, et al. Cardiac surgery in Canada during the COVID-19 pandemic: a guidance statement from the Canadian Society of Cardiac Surgeons. Can J Cardiol. 2020;36(6):952-5. https://doi.org/10.1016/j.cjca. 2020.04.001.

51. Popovic B, Varlot J, Metzdorf PA, Jeulin H, Goehringer $\mathrm{F}$, Camenzind E. Changes in characteristics and management among patients with ST-elevation myocardial infarction due to COVID-19 infection. Catheter
Cardiovasc Interv. 2020. https://doi.org/10.1002/ccd. 29114.

52. Hamadeh A, Aldujeli A, Briedis K, Tecson KM, SanzSanchez J, Al Dujeili M, et al. Characteristics and outcomes in patients presenting with COVID-19 and STsegment elevation myocardial infarction. Am J Cardiol. 2020;131:1-6. https://doi.org/10.1016/j.amjcard. 2020.06.063.

\section{Publisher's Note}

Springer Nature remains neutral with regard to jurisdictional claims in published maps and institutional affiliations. 